\title{
Implementing a Participatory Model of Micro Health Insurance among Rural Poor with Evidence from Nepal
}

\author{
David M. Dror ${ }^{\mathrm{a}, \mathrm{b}}$, Atanu Majumdar ${ }^{\mathrm{a}}$, Pradeep Panda ${ }^{\mathrm{a}}$, Denny John ${ }^{\mathrm{a}}$ and \\ Ruth Koren ${ }^{\mathrm{c}}$ \\ ${ }^{a}$ Micro Insurance Academy, 52B Okhla Industrial Estate, Phase-3, New Delhi 110020, India. \\ ${ }^{\mathrm{b}}$ Erasmus University Rotterdam, Institute of Health Policy and Management, P.O. Box 1738, 3000 DR Rotterdam, \\ The Netherlands. \\ E-mail: daviddror@socialre.org \\ ${ }^{\mathrm{c}}$ Tel Aviv University, Felsenstein Medical Research Center, Sackler Faculty of Medicine, Ramat Aviv, Tel Aviv, \\ Israel.
}

This paper reports on two voluntary, contributory, contextualised, community-based health insurance (CBHI) schemes, launched in Dhading and Banke (Nepal) in 2011. The implementation followed a four-stage process: initiating (baseline survey), involving (awareness generation and engaging community in benefit-package-design), launch (enrolment and training of selected community members) and post-launch (viable claims ratio, settled within satisfactory time, sustainable affiliation). Both schemes were successful on four key parameters: effective planning; affiliation (grew from 0 to $\sim 10,000)$ and renewals ( $>65$ per cent); claims ratio ( $\sim 50$ per cent); and promptness of claim settlement ( 23 days). This model succeeded in implementing CBHI with zero premium subsidies or subsidised health-care costs. The successful operation relied in large part on the fact that members trust that they can enforce this contract. Considerable insurance education and capacity development is necessary before the launch of the CBHI, and for sustainable operations as well as for scaling.

The Geneva Papers (2014) 39, 280-303. doi:10.1057/gpp.2013.31

Keywords: Nepal; micro health insurance; community-based health scheme; benefit package design; health insurance performance indicators; microinsurance implementation process

Article submitted 8 May 2013; accepted 15 October 2013; published online 15 January 2014

The online version of this article is available Open Access

\section{Introduction}

In countries where governments can neither mandate contributory universal health coverage (UHC) nor subsidise its full cost, one of the great challenges is reducing private out-ofpocket expenditure (OPE) for health care payable at the point and time of service. This inequitable and inefficient health financing mechanism ${ }^{1}$ persists in many low-income countries. $^{2}$ In Nepal, the third poorest country in Asia, OPE represents around 72 per cent

\footnotetext{
${ }^{1}$ Garg and Karan (2009)

${ }^{2}$ Xu et al. (2010).
} 
of total health-care costs. ${ }^{3}$ The World Health Organization proposes the introduction of prepayment and risk pooling as a way to solve this problem. ${ }^{4}$ Several experiments with community-based health insurance (CBHI) have been reported ${ }^{5,6,7}$; in Nepal, experiments with CBHI have been carried out since 2004, both in rural and in urban settings. ${ }^{8,9}$ Most projects depended on external subsidies and offered provider-based health insurance with a restricted choice of health-care services. Recently, the Government of Nepal has shown interest in universal health care (UHC) through implementation of health insurance ${ }^{10}$; however, it has neither launched a national scheme nor entered into arrangements with commercial insurers to secure an ample supply of health insurance, notably in difficult-toreach locations. Rather, it has designated several "pilot" districts for experimentation with several models, notably CBHI. This paper addresses the question whether and how it is possible to operate sustainable health insurance in the informal sector in rural Nepal without premium subsidies, and what useful role communities can play in the self-governance of their insurance.

We present here the voluntary and contributory CBHI model that has been piloted in Nepal. The empirical scope covers CBHI operations from 2011 until 2013. The novelty of this implementation model is its combination of high-resolution data collection and analysis, reliance on revenue generation on a voluntary basis rather than on premium subsidies, and capacity development. The conceptual framework of this model includes tailoring benefits to local risks at premiums perceived locally as affordable; involving prospective beneficiaries in benefit package design to ensure that their perceived priorities are given voice; assigning responsibility for governance of the schemes to members, to reduce conflicts of interests and enhance the likelihood that benefits are paid as promised; and localising operations of the scheme at community level with suitable capacity development.

The paper is structured as follows: we provide details on the location, data and methods used in this study, followed by a description of the implementation model. The findings, reflecting the experience during two full years of operation using established performance indicators, follow. We interpret the findings in the discussion section, and end by formulating conclusions, notably on sustainability and scalability of this CBHI implementation model, and its potential contribution to achieving the social policy goals of the Government of Nepal.

\section{Data and methods}

\section{The CBHI schemes studied}

This paper describes the implementation of two schemes: Saubhagya, launched in January 2011 in Dhading district by a consortium composed of Development Project Service Centre

\footnotetext{
${ }^{3}$ World Bank (2007).

${ }^{4}$ World Health Organization (2011).

5 Biener and Eling (2012).

${ }^{6}$ Mahal et al. (2013).

${ }^{7}$ Borghi et al. (2013).

${ }^{8}$ GIZ Health Sector Support Program, Department of Health Services (2012).

${ }^{9}$ Stoermer (2012).

10 "National Health Insurance Policy 2012" of the Government of Nepal.
} 
(DEPROSC), ${ }^{11}$ Micro Insurance Academy (MIA) ${ }^{12}$ and Save the Children Nepal (STC). ${ }^{13}$ Sanjeevni was launched in June 2011 in Banke district by a consortium composed of Nirdhan Utthan Bank (Nirdhan), ${ }^{14}$ MIA and STC.

\section{Data sources}

This paper is based on three data sources.

\section{A baseline study}

Conducted from January to April 2009, it included a household survey, focus group discussions (FGDs) and key informant interviews ${ }^{15}$ to gather information on socio-economic and demographic features, health-seeking patterns and how the local population financed access to health care. A two-stage sampling method was applied. The first entailed purposive selection of "village development committees" (VDC) and wards (administrative divisions smaller than districts) to include the places the field partners designated for implementation of the CBHI schemes. The second stage included selection of intervention and control groups; the intervention groups included those to whom the CBHI was going to be offered (often organised as "self-reliant groups" (SRG) numbering about 15-20 people who were affiliated with DEPROSC in Dhading and with Nirdhan in Banke ${ }^{16}$; the control groups, of equal size, were not invited to join. We call these sub-cohorts "members" and "nonmembers", respectively.

The sample consisted of 1,000 households from Dhading and 1,008 households from Banke. The sample size was calculated based on an error margin of 0.005 (for estimation of the hospitalisation rate with a prior estimated value of 0.04 ), a confidence interval of 80 per cent and a design effect of $2 .{ }^{17}$ We interviewed a members sample comprised of 504 households randomly sampled from 17 VDCs in Banke (from Nirdhan's list), respecting a proportional number of members in the local ward population (member strength in Ward to member strength in VDC) ${ }^{18}$; and a random sample of 500 households in Dhading from the list of DEPROSC members (covering nine VDCs). ${ }^{19}$ The non-members were selected randomly in each village, following the "four winds" method. ${ }^{20}$

For the purpose of analysis of the results of the implementation, only members' household baseline data are used.

\footnotetext{
${ }^{11}$ http://www.deprosc.org.np/Home.aspx

12 http://www.microinsuranceacademy.org/

${ }^{13}$ http://www.savethechildren.org/site/c.8rKLIXMGIpI4E/b.6150545/k.B8DE/Nepal.htm

${ }^{14}$ http://www.nirdhan.com/

15 Dror and Radermacher (2010).

${ }^{16}$ An SRG is a group of 10-15 women who agree to deposit a fixed amount every month in a common kitty. When a member is in need of money, she can borrow the amount from the common kitty. She pays a service charge (equivalent to interest) to the group fund. Each SRG has a bank account in the name of the group.

${ }^{17}$ Cochran (1977).

${ }^{18}$ With the following breakdown by VDC: 99 households in Bageswari, 33 in Banratuwa, 4 in Belbhar, 28 in Chisapani, 12 in Indrapur, 3 in Jaispur, 6 in Khajurapur, 124 in Kohalpur, 24 in Manikapur, 26 in Navabasta, 18 in Paraspur, 12 in Rajapur, 63 in Rajhaina, 10 in Sahigaon, 5 in Samserganj, 20 in Sitapur and 17 in Titanaria.

${ }^{19}$ Breakdown by VDCs was follows: 98 households in Baireni, 12 in Benighat, 21 in Bhumesthan, 21 in Dhusha, 43 in Gajuri, 86 in Jogimara, 42 in Kalleri, 70 in Kumpur, and 107 in Pida.

${ }^{20}$ Som (1996).
} 
Table 1 Socio-demographic profile of respondents

\begin{tabular}{lcc}
\hline & Dhading & Banke \\
\hline MPCC (NPR) & $2402 \pm 77.6$ & $1979 \pm 58.2$ \\
MPCC (PPP\$) & $82 \pm 2.65$ & $68 \pm 1.99$ \\
Total literacy & $81 \%$ & $82 \%$ \\
Female literacy & $75 \%$ & $75 \%$ \\
Average family size & $5.24 \pm 0.06$ & $5.63 \pm 0.08$ \\
House type (permanent structure) & $13 \%$ & $29 \%$ \\
Predominant religion & Hindu & Hindu \\
Predominant language & Nepali & Nepali \\
\hline
\end{tabular}

The average monthly per capita consumption (MPCC) of the members sub-cohorts as per the baseline was Napalese rupees (NPR) 2,402 \pm 77.6 (= purchasing power parity (PPP) $\$ 82 \pm 2.65)$ at Dhading and NPR $1,979 \pm 58.2(=$ PPP $\$ 68 \pm 1.99)$ at Banke. ${ }^{21}$ Estimated literacy rates of members sub-cohorts at Dhading and Banke were 81 and 82 per cent, respectively. The female literacy rate was 75 per cent in both places. The average family size was $5.63( \pm 0.08)$ in Banke and $5.24( \pm 0.06)$ in Dhading. In all, 29 per cent of houses in Banke were permanent housing structures ("pacca houses"), compared with only 13 per cent in Dhading (Table 1).

\section{Results of simulations at the design phase}

During the preparatory stage, a series of simulation exercises were conducted with groups (each of about 15 SRG members) to obtain data on the benefits and compositions that might suit best. The results of these simulation exercises were recorded and served as one data source at various stages of the implementation process.

\section{Actual results of the schemes}

Data was obtained from the books of accounts (e.g. number of paid-up members, premiums collected and payments made to members) and operational records of the CBHI schemes (notably information on number of claims, time needed to process those claims and number of meetings of the claims committees).

\section{Essentials of the implementation model}

The business process of implementation of this CBHI model follows four consecutive stages (see Appendix A).

Initiating: Initiating refers to the preparatory stage in which success implies the garnering of adequate information - on local willingness to pay, incidence of illness and costs-needed for provision of sound actuarial and other technical advice. In Nepal this information was gathered through the baseline study conducted in 2009.

${ }^{21}$ Conversion rate PPP\$ $1=$ NPR 29.25, in year 2009. The per capita per month GNI of Nepal was estimated at 100 PPP\$ for the year 2009. 
Involving: Involving refers to the stage in which success implies that the target groups are able to form consensus on the design and pricing of the benefit package for their community, pursuant to participation in awareness and capacity-building activities. This was done in 2010.

Launch: Launch refers to the stage in which success implies two things: that CBHI members choose some members to be the office-bearers to manage and govern the scheme, and that enrolments reflect the community's consensus that insurance (through the customised benefit package) is better than no insurance.

Post-launch: Post-launch refers to the stage in which success implies that the loss ratio is viable, that claims are settled in a contextually satisfactory time frame, that the income from membership (new and renewals) is adequate to fund sustained operations, that community consensus on the benefit package extends into subsequent years, and that the CBHI has the capacity to satisfy the community's ongoing technical support needs.

At the Initiating stage, the target community agrees to cooperate with an external body in surveying local conditions of risk exposure and perceptions of priorities about risk. Unremunerated interviewees share information; they expect a return, which (in this implementation model) is a promise to propose the insurance that could improve their lives. This engagement with the external organisers establishes agreed roles: the expert collects data and offers knowledge-based recommendations and the community decides on the action. Stated differently, the external expert (in this case the Micro Insurance Academy-MIA) acts as "change maker" and the local community acts as "decisionmaker". The decisions are taken during the Involving stage, when the target group is engaged in benefit package design. The package that communities can compose may differ radically from anything offered by an insurer (if any offer exists at all). The assumption underlying this stage of the process is that, when prospective enrollees can participate in composing the package that reflects their perceived priorities, they will be more willing to affiliate and to pay. For as long as there is no willingness to pay (WTP), there can be no demand; asserting needs without solvent demand leads nowhere, and the necessary condition towards expanding health insurance coverage is that solvent demand exists where none existed before. The essential success of Involving is when the target group reaches consensus that being health-insured is "what we all do", at a price that we all are willing to pay. This also means that Involving is essentially a group decision rather than an individual choice.

Had there been ample competition in the supply of health insurance, the community could have shopped around for the package and price they wanted. But, the supply of insurance to the informal sector in Nepal is insufficient, both in terms of coverage and in terms of premium competition. Therefore, the Launch stage includes a decision by the community to act as "market maker" for the benefit package chosen by its members at the price they are willing to pay. As the community now needs the skills required to operate the scheme, the assistance must include a "competence chain" through which local persons are trained in skills they need to operate the insurance. The key roles are briefly described next.

The "insurance activists" (IAs) are the first line of managing the CBHI scheme; they move from village to village and door to door to enrol members, maintain direct contact with members, provide information, collect premiums, assist members to avail services (e.g. guide to certain health-care providers) and in submitting claims, etc. In Dhading each of the six IAs covers 150 members, while in Banke, each of the five IAs covers 455 members. 
This large gap in member per IA reflects the time/effort required to reach the members in their villages in very different terrains. The IAs are employed by the CBHI and draw a monthly payment.

Another role is that of "insurance coordinator" (IC) who keeps membership records and books of accounts using a management information system provided by MIA, manages the bank account, and may also maintain relationships with health-care providers. From 2011 onwards, one IC was employed in Dhading and two in Banke.

Claims for reimbursement are adjudicated by the "Claims Committee" (CC). The CC is composed of one representative from each VDC where the members live, designated/elected by the "self-reliant groups" to sit on the CC. Candidates must be literate, understand the claims process and be able to make decisions promptly. In Dhading, seven CCs with 42 members were active in 2011, and eight CCs comprising 49 members in 2012, and the increase in 2012 was occasioned by the addition of two VDC populations; in Banke there were five CCs with seven members each operating in 2011 and in 2012. CC members meet once a month and receive a "sitting fee".

Finally, the "Coordination Committee" (CoCo) supervises the overall financial performance of the scheme. The CoCo meets monthly; reviews the financial performance; signs checks, policy documents and claim overview documents ${ }^{22}$; conducts client dispute resolution, etc. In Dhading there was one CoCo, with seven members in 2011 and eight members in 2012. In Banke (where the CoCo is called "Main Committee"), one committee operated with seven members in 2011 and 2012. CoCo members are paid a sitting fee by the scheme.

\section{Results}

The results of the Nepali CBHI schemes are examined here against nine pieces of essential information, some of which follow accepted performance indicators. ${ }^{23}$

\section{Willingness to pay}

Before launching a new CBHI, it is essential to have an estimate of WTP for health insurance among the target group (especially when the expected income from premium subsidies is zero) because WTP is used as a proxy for premiums that define the limits of the benefit package. The baseline survey includes elicitation of WTP. There are several methods to obtain this estimate ${ }^{24}$; we used the descending bidding game method, ${ }^{25}$ which consisted of asking each interviewee how much she/he would agree to pay for health insurance that would cover part of the cost of their health care on the basis that, if you are willing to pay more, you will get more benefits and, if you are willing to pay less, you will get fewer

\footnotetext{
22 The claim overview document is a document generated by the MIS application following submission of a claim. The system validates the claim amount under different benefit heads and calculates the amount payable based on the amount already received by the claimant. This calculation helps the CoCo to verify that decisions on the claim taken by the $\mathrm{CC}$ are fine.

${ }^{23}$ Wipf and Garand (2010).

${ }^{24}$ Dror and Koren (2012).

25 Dror et al. (2007).
} 


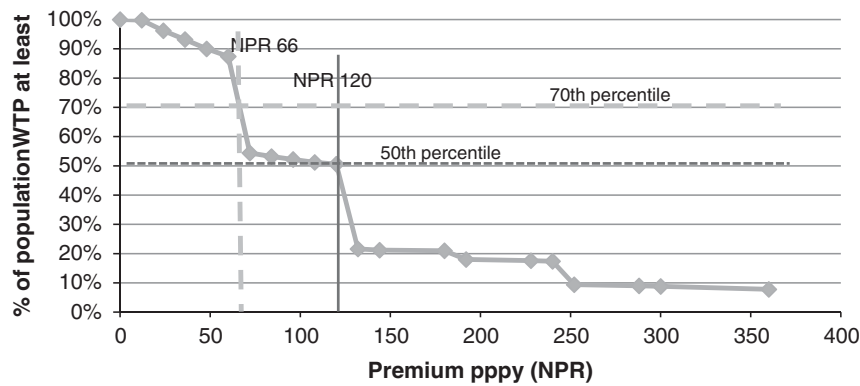

Figure 1. Results of the bidding game for WTP, Saubhagya Dhading.

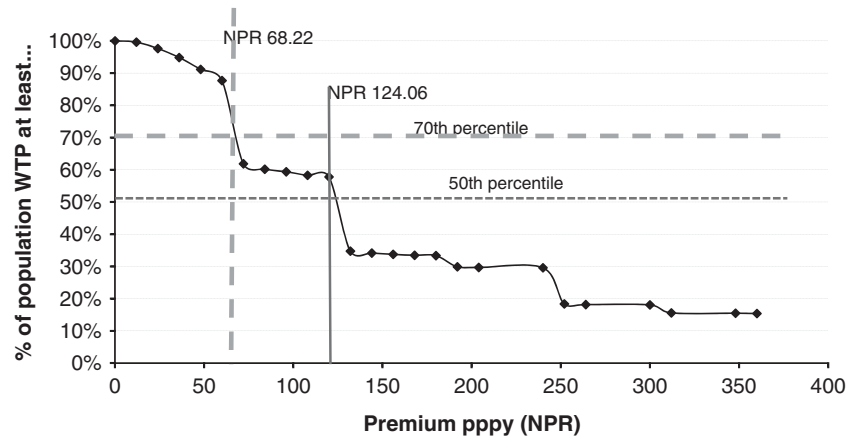

Figure 2. Results of the bidding game for WTP, Sanjeevni Banke.

benefits. The opening bid (of NPR 30 per person per month) ${ }^{26}$ was intended to be refused as too high; when a bid was refused, a lower bid (1 NPR less) was offered, repeatedly, until a bid was accepted or the bid reached NPR 0 . The accepted bid was recorded as the respondent's WTP. The median WTP was NPR 10.0 in Dhading and NPR 10.5 in Banke. All results of the bidding game are shown in Figures 1 and 2.

We also considered another method to estimate WTP, based on mean food expenditure. ${ }^{27}$ The advantage of this method is that it bases the estimate of WTP on actual costs of known goods, rather than on unknown costs of uncertain services. By applying this method in Nepal, the first approximation of WTP was NPR $41 \pm 1$ in Dhading and NPR $38 \pm 1$ in Banke (about 4.5 per cent of mean food expenditure of the target population).

These two estimates of WTP, though markedly different, are taken as the lower and upper boundaries of scheme revenues within which the benefit package can be designed.

\section{Benefit package design and pricing}

It is known that benefit package design is an exercise in rationing limited resources. ${ }^{28}$ Two key issues underlie this rationing exercise: firstly, the benefits must reflect local health needs

\footnotetext{
${ }^{26}$ An indicative exchange rate is $100 \mathrm{NPR}=1 \mathrm{USD}$.

${ }^{27}$ Binnendijk et al. (2013).

${ }^{28}$ Ryan et al. (2001).
} 
and local availability of health services; secondly, the people in the target population must agree to the rationing decisions, as they can refuse enrolment, which is voluntary.

We apply a modified version of a preference elicitation method called CHAT (Choosing Healthplans All Together) that has been successfully applied in many locations in rural India. $^{25,29}$ In the first stage of the process (known as the design workshop stage), the community (through its representatives) is shown many benefit package options, each with a particular premium. Through an iterative process of deliberations, the participants select four to five options that match the needs and WTP of the community. It is noted that the price reflects pure actuarial premiums plus about 30 per cent to cover risk loading and administrative expenses (incurred by the community in running the scheme), but without profit or any other cost (and no payment to MIA). The four or five benefit package options selected in the design workshop are then disseminated in the community (through pictorial paper boards called CHAT Boards; the CHAT board used in 2011 is attached as Appendix B for illustration), for discussion and decision. The package selected by the largest number of groups is retained for the entire scheme. A total of 47 such group discussions took place in Dhading and 81 in Banke. The CHAT and benefit/premium selection process is repeated each year, to allow the communities to adjust their priorities based on experience, and to increase coverage when WTP increases. Prior to preparation of new CHAT boards for 2012, a series of 24 FGDs were conducted in Dhading in June 2012 to elicit opinions on changes in the benefits and premiums for the next year. These FGDs led to proposals ${ }^{30}$ which were considered during the "redesign workshop" by community representatives (CC and CoCo members). The CHAT exercises were administered among enrolled members and among non-members, with the view to enrolling more members.

The package options (those considered and those retained) for 2011 and 2012 are shown in Table 2.

Involving people in the CHAT exercises is a hands-on demonstration of the interplay between premiums on the one hand, and the width of benefits and depth of coverage, on the other. This experience helps manage expectations to realistic dimensions and minimises disappointments with reimbursements.

The premium levels that were chosen by the groups were within the estimated range of WTP (i.e. between NPR 10 and NPR $41 \pm 1$ in Dhading, and between NPR 10.5 and NPR $38 \pm 1$ in Banke) and closer to the higher limits.

As for the package design, the choices clearly favoured broad packages that included both outpatient and inpatient coverage. However, the cost of covering medicines was too high to be retained. The apparent trade-off was to choose a lower cap for hospital reimbursements.

It is also interesting to note that the benefit choices in Dhading and Banke were different from each other in Year 1 and converged towards more similarity in Year 2.

Based on the CHAT choices, the schemes implemented the packages described in Table 3.

It is noteworthy that the Dhading scheme changed the method of calculating caps, from a cap per person per year (pppy) to a dual cap per event (p.e.) and per family per year

\footnotetext{
${ }^{29}$ Danis et al. (2007).

${ }^{30}$ For example, in Dhading in 2012, the community mentioned injury to be a part of the benefit package, and later a survey among 455 members was conducted to calculate the probability and cost of injury.
} 
Table 2 Benefit package options and premiums-including final selection per year per community (in Nepalese rupees)

\begin{tabular}{|c|c|c|c|c|c|c|c|c|c|c|c|c|c|c|c|c|c|c|c|}
\hline \multirow[t]{3}{*}{ Benefit options } & \multicolumn{10}{|c|}{ Dhading } & \multicolumn{9}{|c|}{ Banke } \\
\hline & \multicolumn{5}{|c|}{2011} & \multicolumn{5}{|c|}{2012} & \multicolumn{5}{|c|}{2011} & \multicolumn{4}{|c|}{2012} \\
\hline & 1 & 2 & 3 & 4 & 5 & 1 & 2 & 3 & 4 & 5 & 1 & 2 & 3 & 4 & 5 & 1 & 2 & 3 & 4 \\
\hline Hospitalisation & 5,000 & 4,000 & 5,000 & 6,000 & 4,000 & 2,500 & 3,000 & 4,000 & 5,000 & 2,500 & 2,000 & 4,000 & 5,000 & 4,000 & 5,000 & 2,500 & 4,000 & 3,000 & 2,000 \\
\hline Imaging & & 500 & & 400 & 500 & 400 & 600 & 700 & 600 & 400 & 250 & 500 & 1,000 & 1,000 & 1,000 & 300 & 250 & 400 & 600 \\
\hline Lab tests & 600 & 250 & 400 & & 250 & 250 & 400 & 500 & 400 & 250 & 200 & 250 & 250 & 500 & 1,000 & 200 & 200 & 250 & 400 \\
\hline Transport & & & 200 & & 400 & & 300 & & 200 & & 100 & & & & 100 & 200 & 200 & 200 & 200 \\
\hline Medicines & & & & & & & & & & 500 & & & & & & & & & \\
\hline Premium PPPM $^{\mathrm{a}}$ & 23.1 & 24.5 & 24.7 & 25.4 & 26.2 & 21.1 & 28 & 31.7 & 34.3 & 76.4 & 20 & 30.3 & 35.1 & 36.1 & 38.8 & 28.3 & 33.3 & 33.8 & 35 \\
\hline Groups chose this & $3 / 47$ & 0 & $7 / 47$ & 0 & $37 / 47$ & $7 / 91$ & $78 / 91$ & $1 / 91$ & $2 / 91$ & $3 / 91$ & $40 / 81$ & $5 / 81$ & 0 & $4 / 81$ & $32 / 81$ & $9 / 180$ & $7 / 180$ & $1 / 180$ & $163 / 180$ \\
\hline$\%$ of group choices & $6 \%$ & $0 \%$ & $15 \%$ & $0 \%$ & $79 \%$ & $8 \%$ & $86 \%$ & $1 \%$ & $2 \%$ & $3 \%$ & $49 \%$ & $6 \%$ & $0 \%$ & $5 \%$ & $40 \%$ & $5 \%$ & $4 \%$ & $1 \%$ & $90 \%$ \\
\hline Final selection & & & & & $\checkmark$ & & $\checkmark$ & & & & $\checkmark$ & & & & & & & & $\checkmark$ \\
\hline
\end{tabular}

${ }^{\text {a }}$ Per person per month: During the CHAT, the premiums paid per month are shown to the community for the purpose of simplicity. 
Table 3 The implemented benefits packages

\begin{tabular}{|c|c|c|c|c|c|}
\hline \multirow[t]{2}{*}{ Benefit type } & \multirow[t]{2}{*}{ Conditions } & \multicolumn{2}{|c|}{ Year 1} & \multicolumn{2}{|c|}{ Year 2} \\
\hline & & $\begin{array}{c}\text { Banke } \\
\text { Sanjeevni }\end{array}$ & $\begin{array}{l}\text { Dhading } \\
\text { Saubhagya }\end{array}$ & $\begin{array}{c}\text { Banke } \\
\text { Sanjeevni }\end{array}$ & $\begin{array}{c}\text { Dhading } \\
\text { Saubhagya }\end{array}$ \\
\hline $\begin{array}{l}\text { Hospitalisation } \\
\text { benefit }\end{array}$ & $\begin{array}{l}\text { All hospitalisations }>24 \text { h covered; only from } \\
\text { selected hospitals: government and private; all } \\
\text { direct hospital costs covered; hospital bill + } \\
\text { medicines needed and bought during } \\
\text { hospitalisation in pharmacy outside hospital + } \\
\text { tests and imaging prescribed and done during } \\
\text { hospitalisation in testing centre outside hospital }\end{array}$ & $\begin{array}{l}\text { pppy }^{\mathrm{a}}: \\
\text { NPR } \\
2,000\end{array}$ & $\begin{array}{l}\text { pppy: NPR } \\
4,000\end{array}$ & $\begin{array}{l}\text { pppy: } \\
\text { NPR } \\
2,000\end{array}$ & $\begin{array}{l}\text { p.e. }^{\text {b. }} \\
3,000 ; \\
\text { pfpy: } \\
20,000\end{array}$ \\
\hline $\begin{array}{l}\text { Transportation } \\
\text { benefit }\end{array}$ & $\begin{array}{l}\text { A one-time flat amount compensation for } \\
\text { transportation costs for all hospitalisations of at } \\
\text { least } 24 \mathrm{~h}\end{array}$ & NPR 100 & NPR 400 & NPR 200 & NPR 300 \\
\hline $\begin{array}{l}\text { Imaging tests } \\
\text { benefit }\end{array}$ & $\begin{array}{l}\text { Imaging test prescribed by the doctors of selected } \\
\text { hospitals and done in an outpatient setting (not } \\
\text { during hospitalisation of more than } 24 \mathrm{~h} \text { ) }\end{array}$ & $\begin{array}{l}\text { pppy: } \\
\text { NPR } 250\end{array}$ & $\begin{array}{l}\text { pppy: NPR } \\
500\end{array}$ & $\begin{array}{l}\text { pppy: } \\
\text { NPR } 600\end{array}$ & $\begin{array}{l}\text { p.e.: NPR } \\
600 ; \text { pfpy }^{c} \text { : } \\
3,000\end{array}$ \\
\hline $\begin{array}{l}\text { Lab tests } \\
\text { benefit }\end{array}$ & $\begin{array}{l}\text { Lab tests prescribed by the doctors of selected } \\
\text { hospitals and done in an outpatient setting (not } \\
\text { during hospitalisation of more than } 24 \mathrm{~h} \text { ) }\end{array}$ & $\begin{array}{l}\text { pppy: } \\
\text { NPR } 200\end{array}$ & $\begin{array}{l}\text { pppy: NPR } \\
250\end{array}$ & $\begin{array}{l}\text { pppy: } \\
\text { NPR } 400\end{array}$ & $\begin{array}{l}\text { p.e.: NPR } \\
\text { 400; pfpy: } \\
3,000\end{array}$ \\
\hline
\end{tabular}

${ }^{\mathrm{a}}$ pppy $=$ maximum amount insurance will pay out per person per year.

b.e. = maximum amount insurance will pay per event.

${ }^{c}$ pfpy $=$ maximum amount insurance will pay out per family per year.

(pfpy). This method of calculating the benefit, called "family floater", 31 increases the coverage amount available to sick individuals within a family unit; yet, there is no evidence thus far of adverse selection, with the notable exception that family size of the insured is smaller than expected, when larger family size could have been expected. One lesson might be to link the application of the family floater with an obligation to affiliate entire families, which could reduce the financial risk for the scheme and enhance the inclusive nature of the scheme.

\section{Membership in the CBHI}

Enrolment into the schemes was open during "affiliation periods" lasting two months; enrolment was not possible outside these affiliation periods. The evolution of membership numbers until 31 January 2013 is shown in Table 4.

Overall, membership numbers doubled from Year 1 (2011) to Year 2 (2012), with satisfactory renewal rates in Dhading, and relatively lower rates in Banke.

${ }^{31}$ In a family floater policy, the cap limits total payout to the family, instead of an event or an individual. In case someone becomes sick multiple times, she/he can take advantage of the higher per family cover. 
Table 4 Membership in the CBHIs

\begin{tabular}{|c|c|c|c|c|c|c|c|c|}
\hline \multirow[t]{2}{*}{ Enrolment period } & \multicolumn{3}{|c|}{$\begin{array}{c}\text { Enrolment } \\
\text { status }\end{array}$} & \multicolumn{2}{|c|}{$\begin{array}{c}\text { Total members } \\
\text { per scheme }\end{array}$} & \multicolumn{2}{|c|}{ Renewal \% } & \multirow[t]{2}{*}{$\begin{array}{c}\text { Total } \\
\text { project }\end{array}$} \\
\hline & New & Renew & Total & $\begin{array}{c}\text { Saubhagya } \\
\text { Dhading }\end{array}$ & $\begin{array}{c}\text { Sanjeevni } \\
\text { Banke }\end{array}$ & $\begin{array}{c}\text { Saubhagya } \\
\text { Dhading }\end{array}$ & $\begin{array}{c}\text { Sanjeevni } \\
\text { Banke }\end{array}$ & \\
\hline 2011 January & 514 & & 514 & 514 & & & & 514 \\
\hline 2011 June & 4,176 & & & & 4,176 & & & 4,690 \\
\hline 2011 July & 394 & & 394 & 908 & & & & 5,084 \\
\hline 2012 January & 1,066 & 349 & 1,415 & 1,809 & & $67.9 \%$ & & 5,985 \\
\hline 2012 June & 5,818 & 2,063 & & & 7,881 & & $49.4 \%$ & 9,690 \\
\hline 2012 July & 391 & 254 & 645 & 2,060 & & $64.5 \%$ & & 9,941 \\
\hline 2013 January & 1,753 & 965 & 2,718 & 3,363 & & $68.2 \%$ & & 11,244 \\
\hline 31 Dec. 2011 & & & & & & & & 5,084 \\
\hline 31 Dec. 2012 & & & & & & & & 9,941 \\
\hline 31 Jan. 2013 & & & & & & & & 11,244 \\
\hline
\end{tabular}

\section{Household size of the insured population}

The mean household size of the members sub-cohort in the baseline survey was $5.24 \pm 0.063$ in Dhading and 5.63 \pm 0.075 in Banke (data sourced from baseline survey). Surprisingly, the average household size of enrolled members was significantly lower, at $2.85 \pm 0.035$ in Dhading and 2.44 \pm 0.019 in Banke (obtained from membership records). This big difference raises the question which demographic segment has been excluded by families.

Table 5, providing the age and gender distributions of the two groups (the sampled "member" sub-cohort in the household survey vs the actual CBHI membership), shows clearly that adult women are over-represented in the insured cohort, compared with men and with their proportion in the overall population (household survey data). And, young girls are under-represented among the insured, compared both with young boys and with their share in the population.

\section{Incidence of claims}

We compare the expected and actual incidence of claims for the three main benefit types that formed the basis of members' benefits premium package choice, based on two years' experience. The results are summarised in Table 6.

The agreement between expected and actual incidence of hospital claims is very good in Banke and in the second batch of affiliation in Dhading; the first batch of enrollees in Dhading had lower incidence than expected, which may reflect that the number of enrolled was too small to represent the target group correctly.

As for imaging and lab claims, actual incidence was lower than expected in Banke, and this could explain the decision of both schemes to increase the cap for this benefit in Year 2, to offset the lower incidence by higher reimbursement at a similar premium. This suggests that the insured understood the pricing mechanism very well. The agreement between expected and observed number of claims suggests that adverse selection, moral hazard and 
Table 5 Age and gender distribution ("members" cohort in the household survey vs insured population)

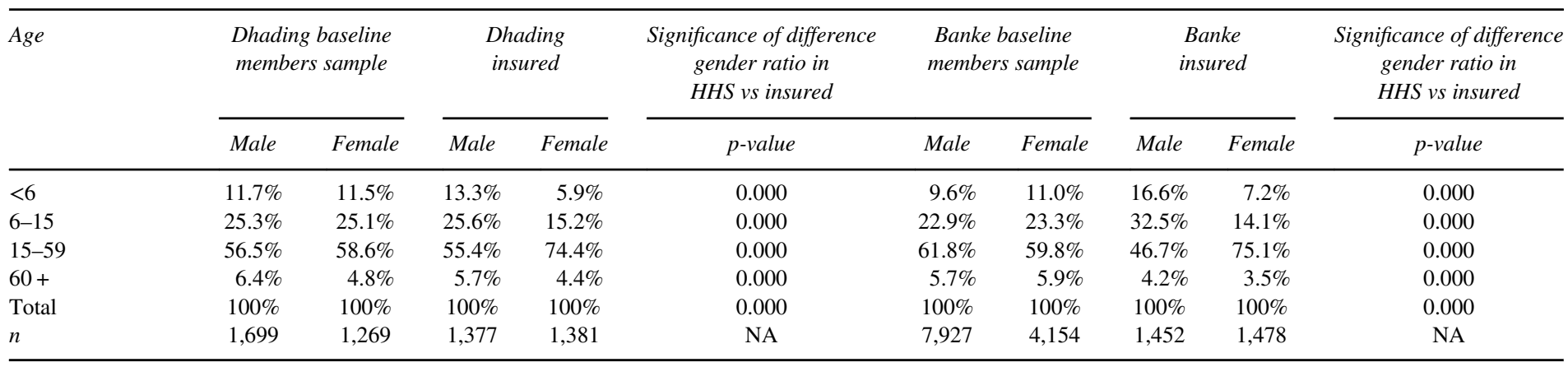


The Geneva Papers on Risk and Insurance-Issues and Practice

292

Table 6 Comparison between expected and actual incidence of claims

\begin{tabular}{|c|c|c|c|c|c|c|c|c|c|}
\hline \multirow{2}{*}{$\begin{array}{l}\text { Incidence } \\
\text { district }\end{array}$} & \multicolumn{3}{|c|}{ Hospitalisations } & \multicolumn{3}{|c|}{ Imaging } & \multicolumn{3}{|c|}{ Lab tests } \\
\hline & $\begin{array}{c}\text { Actual } \\
(\%)\end{array}$ & $\begin{array}{c}\text { Expected } \\
(\%)\end{array}$ & $p$-value ${ }^{\mathrm{a}}$ & $\begin{array}{c}\text { Actual } \\
(\%)\end{array}$ & $\begin{array}{c}\text { Expected } \\
(\%)\end{array}$ & $p$-value ${ }^{\mathrm{a}}$ & $\begin{array}{c}\text { Actual } \\
(\%)\end{array}$ & $\begin{array}{c}\text { Expected } \\
(\%)\end{array}$ & $p$-value $e^{\mathrm{a}}$ \\
\hline Dhading (January 2011) & 2.1 & 3.7 & 0.225 & 13.4 & 15.9 & 0.484 & 10.5 & 18.5 & 0.001 \\
\hline Dhading (July 2011) & 3.3 & 3.7 & 0.934 & 18.3 & 15.9 & 0.587 & 10.9 & 18.5 & 0.006 \\
\hline Banke (June 2011) & 3.3 & 3.1 & 0.878 & 14.8 & 22.2 & 0.000 & 11.8 & 34.1 & 0.000 \\
\hline
\end{tabular}

${ }^{\mathrm{a} C h i}$-square test.

Table 7 Comparison between expected and actual cost of claims

\begin{tabular}{|c|c|c|c|c|c|c|}
\hline \multirow{2}{*}{$\begin{array}{l}\text { Mean cost per claim } \\
(N P R) \\
\text { district }\end{array}$} & \multicolumn{2}{|c|}{ Hospitalisations } & \multicolumn{2}{|c|}{ Imaging } & \multicolumn{2}{|c|}{$L a b$} \\
\hline & $\begin{array}{c}\text { Actual } \\
\text { (paid) } \pm \\
S E M^{\mathrm{a}}\end{array}$ & $\begin{array}{c}\text { Expected } \pm \\
\text { SEM }\end{array}$ & $\begin{array}{c}\text { Actual } \pm \\
\text { SEM }\end{array}$ & $\begin{array}{c}\text { Expected } \pm \\
\text { SEM }\end{array}$ & $\begin{array}{c}\text { Actual } \pm \\
\text { SEM }\end{array}$ & $\begin{array}{l}\text { Expected } \pm \\
\text { SEM }\end{array}$ \\
\hline Dhading (January 2011) & $3094 \pm 356$ & $3303 \pm 106$ & $332 \pm 18$ & $395 \pm 25$ & $198 \pm 10$ & $197 \pm 10$ \\
\hline Dhading (July 2011) & $3250 \pm 302$ & $3303 \pm 106$ & $313 \pm 17$ & $395 \pm 25$ & $217 \pm 9$ & $197 \pm 10$ \\
\hline Banke (June 2011) & $1665 \pm 45$ & $1853 \pm 34$ & $225 \pm 2$ & $228 \pm 6$ & $162 \pm 5$ & $161 \pm 6$ \\
\hline
\end{tabular}

${ }^{\mathrm{a}} \mathrm{SEM}=$ standard error of the mean.

fraud seem to be in good control. This is an interesting observation, which may reflect community governance of the scheme.

\section{Cost of reimbursable claims}

The actual costs paid by the CBHI schemes were compared with the expected costs that were simulated by using the members cohort in the household data, applying identical insurance rules (results shown in Table 7).

As can be seen, the actual and expected average costs per claim are remarkably similar, even though, in three cases, the difference is significant (unpaired Student's t-test). These results confirm that it is possible to base the actuarial calculations underlying package design on the baseline data.

\section{Loss ratio (a.k.a. claims ratio)}

Loss ratio (i.e. the amount paid as benefits divided by the total premium income) is a measure of the financial stability of the scheme, providing an indication of the adequacy of premiums charged relative to underwritten risk. The data shown (Table 8) refers to the first full year for which all claims were settled. The loss ratio is satisfactory and confirms that the two schemes collected suitable premiums. Note that in Dhading, the loss ratio of the second batch of enrollees was 56.7 per cent, higher by about 40 per cent from the first batch (with 40 per cent), but still within a very suitable range. 
Table 8 Loss ratio (a.k.a. claims ratio) for the first year

\begin{tabular}{lccccc}
\hline Location & $\begin{array}{c}\text { No. of } \\
\text { insured }\end{array}$ & $\begin{array}{c}\text { Premium income } \\
\text { (in NPR) }\end{array}$ & $\begin{array}{c}\text { No. of } \\
\text { claims }\end{array}$ & $\begin{array}{c}\text { Claim amount } \\
\text { (in NPR) }\end{array}$ & $\begin{array}{c}\text { Loss } \\
\text { ratio (\%) }\end{array}$ \\
\hline Dhading (January 2011) & 514 & 172,704 & 104 & 69,063 & 40.0 \\
Dhading (July 2011) & 394 & 132,384 & 104 & 74,998 & 56.7 \\
Banke (June 2011) & 4,177 & $1,052,352$ & 810 & 461,830 & 43.9 \\
\hline
\end{tabular}

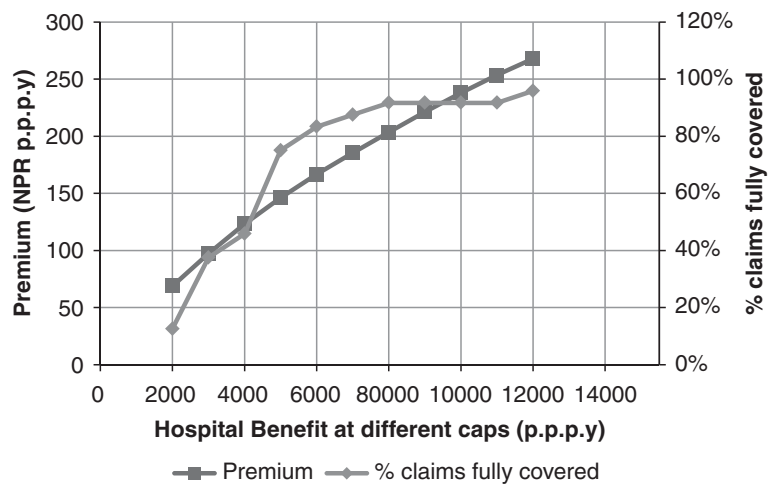

Figure 3. Coverage levels at different caps/hospitalisations (Dhading).

\section{Value for money}

One way to express "value for money" for the insured is to look at the probability that the claims submitted will be fully reimbursed. It is self-explanatory that the cap is designed to curtail some costs, and the probability of full reimbursement increases as the cap increases, but so do the premiums. The outcomes were as follows: in Dhading, in 2011 (the first year for which all claims were settled), 48 per cent of hospitalisations were fully reimbursed; in Banke, the rate was 41 per cent. This coverage seems too low. The share of claims that would have been fully paid at different levels of the cap, and the corresponding premiums are shown in Figures 3 and 4.

As can be seen, a small increase in a low cap occasions relatively better coverage for a modest premium increase, since the two lines in the graph are not parallel or linear (e.g. the range from 4,000 to $6,000 \approx \mathrm{PPP} \$ 136.80$ to PPP\$205.10). For example, had the cap been increased from NPR 4,000 to NPR 5,000 in Dhading, 78 per cent of hospital claims would have been fully covered, while the premium would have increased by only NPR 23 pppy (from NPR 123 to 146).

In Dhading, some 89 per cent of imaging claims were fully covered with a cap of 500, and in Banke, only 24 per cent were fully covered when the cap was 250 . It is interesting to note that both CBHI schemes chose a cap of 600 in 2012; this corrective choice seems suitable for Banke, but less necessary for Dhading. Finally, 45 per cent of lab claims in Dhading were fully covered (with a cap of 250), and 34 per cent in Banke (cap of 200). Both schemes chose to raise the cap to 400 in the following year. The involvement of communities in package 


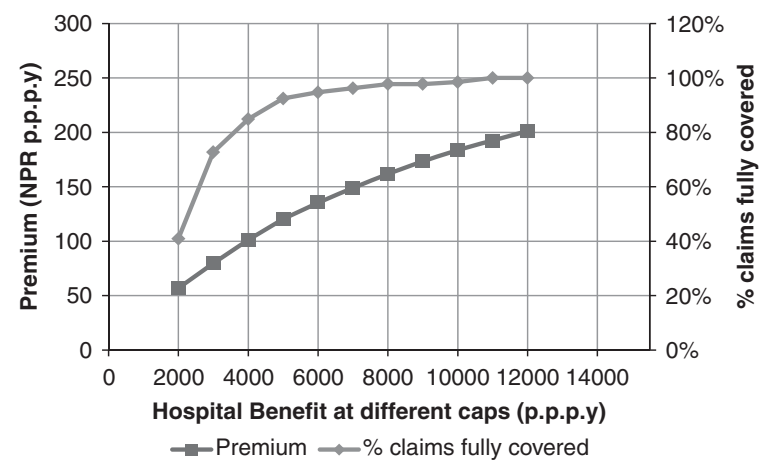

Figure 4. Coverage levels at different caps/hospitalisations (Banke).

Table 9 Promptness of claims reimbursement

\begin{tabular}{llcccc}
\hline Scheme district & $\begin{array}{l}\text { Enrolment } \\
\text { period }\end{array}$ & $\begin{array}{c}\text { Batch } \\
\text { covered } \\
\text { (months) }\end{array}$ & $\begin{array}{c}\text { \# Days from } \\
\text { submission to } \\
\text { CC decision }\end{array}$ & $\begin{array}{c}\text { \# Days from } \\
\text { CC decision } \\
\text { to payment }\end{array}$ & $\begin{array}{c}\text { \# Days from } \\
\text { submission to } \\
\text { payment }\end{array}$ \\
\cline { 3 - 5 } & & & Mean \pm SEM & Mean \pm SEM & Mean \pm SEM \\
\hline Saubhagya Dhading & January 2011 & 12 & $14 \pm 0.98$ & $15 \pm 0.72$ & $28 \pm 1.08$ \\
& July 2011 & 12 & $10 \pm 0.80$ & $12 \pm 0.44$ & $23 \pm 0.85$ \\
& January 2012 & 10 & $10 \pm 0.42$ & $11 \pm 0.22$ & $21 \pm 0.48$ \\
& July 2012 & 4 & $11 \pm 0.95$ & $12 \pm 0.48$ & $24 \pm 1.21$ \\
Sanjeevni Banke & June 2011 & 12 & $13 \pm 0.35$ & $11 \pm 0.27$ & $24 \pm 0.42$ \\
& June 2012 & 5 & $13 \pm 0.38$ & $10 \pm 0.18$ & $24 \pm 0.46$ \\
\hline
\end{tabular}

revision offered the opportunity to adjust perceived value for money and the resulting interest to remain insured.

\section{Members' experience of the claims process}

Of 810 claims submitted in Dhading, only four claims were rejected (less than half of 1 per cent, due to client fraud or incomplete bills submitted by members). No claim rejections were registered in Banke.

Another way of measuring the experience of insured persons is the time interval between claim submission and reimbursement. We measured promptness in three distinct ways: firstly, how long it took from submission to the IA until the claims were decided by the $\mathrm{CC}$; secondly, the delay from decision by the $\mathrm{CC}$ to actual payment to members; and thirdly, the promptness of the entire process from a member's claim submission until reimbursement. The results are shown in Table 9.

Bills were paid within one month on average. Considering that the $\mathrm{CC}$ meets once a month and that the IA needs to visit villages to collect claims and prepare them for decisions, and 
that cash payments are made to members at doorstep, the promptness of the process seems remarkable. Promptness could hardly improve if payments should continue to be made through personal interaction at doorstep, recalling the objective difficulties of travelling to remote villages and the scarce number of CBHI staff.

\section{Discussion}

This paper describes the implementation of two contributory, voluntary, context-adapted and demand-driven health insurance schemes in rural Nepal. The two locations differ from each other in many ways: Dhading is hilly whereas Banke is in the plain; Banke is relatively poorer in terms of MPCC, but has more availability of health-care providers. The differences were also reflected in the choice of benefit package. Owing to these reasons, instead of combining the results of two districts, we preferred to show them separately. These differences notwithstanding, the implementation of CBHI in both locations has been successful. The implementation model is founded on a partnership model (where all parties get a share of the productivity gains from pooling) through the application of the following components: (i) trusted governance at local level; mobilising local rules-in-use and local staff to manage the mutual model with no or few conflicts of interests typical to insurance; (ii) combining "awareness chain" (affiliation-enhancing insurance literacy ${ }^{32}$ with a "value chain" (comprehensible value proposition of insurance) and with a "competence chain" (capacity development of local persons); (iii) context-relevance in pricing and prioritysetting of the risks covered, enabling both a contextualised rationing of partial benefits and gaining credibility by involving prospective enrollees in design and pricing.

The unique feature of this implementation model is its design to achieve three objectives: (i) enabling target communities to take decisions that affect their members' lives (in context, this means deciding on the composition of their benefit package and its price); (ii) enabling communities to be in control of the money paid by members to the CBHI (to reduce concerns about leakages, fraud or corruption); and (iii) enabling communities to control that the predefined rules of the game are followed (in context, this means local governance of daily operations of the insurance). The following five critical conditions serve as benchmarks to review the success of the schemes in achieving these objectives.

\section{The coverage should deal with risks of the insured}

This condition means covering risks that the target group prioritises. The dialog with the target population on rationing, WTP and priority-setting must be based on local riskexposure, that is, morbidity, provision and health-care costs. The data (Tables 6 and 7) demonstrate significant differences across the two locations, a situation already reported in other contexts. ${ }^{33}$ The external change maker was responsible for structuring data acquisition and calculating premiums for different benefit options (a role requiring statistical and actuarial expertise), and the target community provided the information and then took the lead in making choices. The benefits (e.g. hospitalisation, imaging, lab tests, wage loss,

\footnotetext{
32 Panda et al. (2013).

${ }^{33}$ Dror et al. (2008).
} 
transportation, etc.) were chosen in two stages, first (rough cut) by community leaders, followed by a selection by small groups; the package selected by most groups was then retained as the one package applying to all. This interactive process of involving prospective insureds in package design, while time-consuming and labour-intensive, increased the population's understanding about the insurance. The "design workshop" (renamed "redesign workshop" when repeated the following year) enabled insured members to modify their choices based on their actual experience. For example, in Dhading in Year 2, members decided to increase the imaging cap from NPR 500 to 600 and in Banke, from NPR 250 to 600 (Table 2). It is noteworthy that in both schemes and in both years, the outpatient benefits included represented about half the premium cost (e.g. lab tests and imaging; premium data not shown). This package composition differs considerably from what most commercial schemes cover (only inpatient care). Recalling that low enrolment among commercial "microinsurance" schemes was due to the limited coverage of outpatient care, ${ }^{34}$ the involvement of CBHI members in package design in these schemes led to a different priority-setting.

\section{The price should be affordable}

Affordability is what each target group considers as the acceptable price for its unique variant of health insurance. We assessed this by obtaining two estimates of WTP, one by applying a "descending bidding game" (one method of contingent valuation) as part of data collection, and the second by applying a novel alternative method to proxy WTP for health insurance as an estimated 4.5 per cent of mean food expenditure. ${ }^{27}$ The premiums presented to the target groups in the design workshops were between these two estimates of WTP (see Figures 1 and 2). The members chose benefit packages that commanded premiums closer to the higher WTP estimate (premiums were NPR 26.2 and 28 in Dhading, and NPR 20 and 35 in Banke, respectively for the first and second enrolment periods; upper and lower WTP estimates were NPR 41 and NPR 10 pppm in Dhading; and NPR 38 and 10.46 pppm in Banke). We think that the lively group discussions (occasioned by involving so many community members in the process of choice) enhanced the understanding of the trade-off between premiums payable and the depth and width of coverage, and encouraged agreement to pay higher premiums in both schemes in the second year. This could suggest that WTP increases when the insured population gains useful experience with insurance over time (but the effect is not uniform). It is also noted that the premiums chosen in both locations even in Year 2 are lower than the highest estimate of WTP.

Another aspect of affordability is that administrative costs did not include profits to intermediaries or underwriters.

\section{The value proposition of insurance should be positive and clear}

We consider membership numbers (new and renewals, Table 4) as a strong indicator of a positive perception of the value proposition by the target population. In Dhading, membership rose from 514 to 2,060 (+300 per cent) in July 2012 and to 3,363 (+ 554 per cent) by end January 2013, and in Banke the membership rose from 4,176 in Year 1 to 7,881 in Year 2 (+90 per cent). Renewals were voluntary, and rates were around 66 per cent in Dhading and

\footnotetext{
${ }^{34}$ Pott and Holtz (2013).
} 
49.4 per cent in Banke; there is scope for improvement. The household size of the target population was much larger than the average size of insured households (5.2 vs 2.9 lives in Dhading, and 5.6 vs 2.4 in Banke). The insured members (SRG women) did not avail of the opportunity to insure all their household members; the under-6 young girls were underrepresented (Table 5). The traditional hierarchy in allocating resources within the family (lower allocation to girl children) is reflected in this context of considering the value proposition of insurance. Changing this perception will require more group discussions.

Another aspect of the value proposition of insurance is the share of premiums paid back to members (loss ratio); these ratios are of course very sensitive to caps, and the increases of caps for outpatient services that were adopted in Year 2 suggest that the target population fully understood this relationship. Finally, prompt reimbursement added to the sense of value, as members were less exposed to secure interim financing through loans.

\section{The process is transparent and trusted by the insured}

The transparency of the business process was enhanced by placing the operations of the scheme in the hands of members chosen by other members for their posts. Putting the operation and governance in the hands of members (formally a mutual-aid model) removes some conflicts of interest that exist in the partner-agent model, provided that the managers of the scheme run it well. The symbiosis between communities (the decision-makers) and the external facilitator (the change maker) made it possible to deliver tailored training to trusted officials that the community chose so that they would perform effectively, efficiently and locally. The training costs are not paid by the community, and the capacity-development activities are an essential part of this implementation model. The operative assumption underlying the inclusion of a "competencies chain" in the implementation model is that, with time, increased autonomy and self-reliance of communities in running their insurance schemes will allow the phasing out of technical assistance. And the development assumption is that the front-loaded costs in developing local capacity is a justified and essential phase towards achieving the development goals of better access to health care by rural people.

\section{Viable supply and solvent demand could be established}

The reports of other (micro) health insurance projects in Nepal (referenced earlier) suggest several unsuccessful attempts, even with external subsidies. The remarkable achievement reported here is that in similar terrain and difficult conditions, two rural communities, composed mostly of poor persons with low education and no prior exposure to health insurance, succeeded in organising and paying for a viable supply of health insurance where no (commercial) insurer was willing to underwrite risk. Moreover, they did this by respecting a perfect match between local solvent demand, and local prioritisation of benefits. Thirdly, the communities demonstrated their ability to govern a scheme transparently and responsibly. The net result was that the communities used new competencies to consolidate all the conditions to establish and operate a market for health insurance benefitting all concerned where none existed before. The implementation model does not entail any subsidy to premiums, yet operations have been sustainable and have grown from year to year. The technical and actuarial advice provided to the communities during the inception years was essential in ensuring viable insurance operations. These costs are in fact development costs, 
to create a nascent market for health insurance; they cannot and should not be borne by the rural poor, protagonists of this development. In passing, we add that the costs are lower than benchmarks for operating health insurance in other settings.

This study is subject to certain limitations as well. For one, this study described the successful operation of two stand-alone CBHIs. Previous studies flagged that small standalone schemes could have solvency issues. ${ }^{35}$ The Nepali CBHIs are, of course, exposed to this risk as well. The solution could be creating a mutual reinsurance fund to pool outlier risks. That option might be politically more pertinent when more people become insured by CBHIs. Secondly, the analysis of the outcome is using claims data of the first full year, but the first year may differ from subsequent years.

\section{Conclusions}

The argument has been made that poor people demand a development process driven by their communities. ${ }^{36}$ This article provides empirical evidence of the development of health insurance driven by the beneficiary communities in rural Nepal.

After more than two years of operation, the CBHI schemes have been successful in retaining many/most enrollees beyond the original one-year contract and in attracting many new enrollees. This was achieved without premium subsidies and on a voluntary basis, as members agreed to pay health insurance premiums. From a development perspective, this is a remarkable and rare demonstration that contributory health insurance without premium subsidies can be attractive to rural poor in a low-income country. It is also a demonstration that when the target population is involved in priority-setting and pricing, partial coverage is financially and administratively possible. This voluntary, contributory, needs-based and demand-driven implementation model met with a very good response at the grassroots level, and responds to the wishes of the communities to retain decisions, funds, priorities and operations locally. The experience offers evidence of success in overcoming the single most challenging obstacle to UHC in the informal sector in low-income countries, namely, generating contributions from rural poor populations.

This positive evaluation notwithstanding, the verdict is still out whether these CBHI schemes can keep a similar score in the long term. This is similar to the question, on many minds, whether the unknown sportsman that hit a new record is the new champion, or maybe just the one-off lucky beginner. The undisputed facts are the positive results posted and the small-scale size of these implementations. Can this model be replicated to provide health insurance coverage to the majority of the Nepalese population living on less than $\$ 2$ per day? The answer is unclear at this stage, mainly because scaling will require financial resources to provide technical assistance to enable communities become the decision-makers and market makers. The social change of bringing rural persons to manage mutual insurance is not intuitive, and birthing it must be funded as development aid, not as administrative loading. Considering that the Government of Nepal intends to reach UHC and must generate resources through contributions from the beneficiaries, we submit and conclude that the

\footnotetext{
35 Dror and Armstrong (2006).

${ }^{36}$ Narayan et al. (2000).
} 
CBHI model described here could make a definite contribution to achieving social policy goals of Nepal.

\section{Acknowledgements}

The authors gratefully acknowledge the financial, technical and administrative support without which this study could not have been carried out, including: funding by Rockefeller Foundation New York ${ }^{37}$ (grant No. 2008 PHS 229 to Prof. David Dror via Erasmus University Rotterdam) and a grant from an anonymous donor to Save the Children USA (sub-grant \#31531-01) to complete the baseline study (development of questionnaires, data collection and cleaning, analysis and report writing) in 2009/ 2010; funding from the German Ministry of International Cooperation (BMZ) through MISEREOR (the German Catholic Bishops' Organisation for Development Cooperation ${ }^{38}$ ) (grant No. 323-900-1098 ZG, 2011) to support the costs of initiating, involving, launching and operating the schemes during 2010-2012, as well as the cost of Open Access publication. The Micro Insurance Academy has been providing steering, ongoing technical, statistical and other assistance to the CBHI project and to field partners at all the stages. Mr. Ralf Radermacher of MIA led the initial development stages; Ms. Dhriti Bhatta and later Mr. Vikram Patil (MIA staff) provided backstopping and project management of the implementation process. Save the Children (Nepal Country Office) provided logistical support; Dr. Harihar Dev Pant, Chairman of Nirdhan Utthan Bank Ltd and his team in Nepalganj branch, Banke, as well as Mr. Kailash Rijal, Deputy Director of DEPROSC and his team in Dhading, the field partners, were instrumental in securing the cooperation of the members and their field staff. Dr. Lucy Firth (lead economist, MIA) offered insightful in-house editorial peer-review before submission for publication. Two anonymous peer reviewers also offered useful comments. Thanks to all.

\section{References}

Biener, C. and Eling, M. (2012) 'Insurability in microinsurance markets: An analysis of problems and potential solutions', The Geneva Papers on Risk and Insurance-Issues and Practice 37(1): 77-107.

Binnendijk, E., Dror, D.M., Gerelle, E. and Koren, R. (2013) 'Estimating willingness to pay for health insurance among rural poor in India by reference to Engel's law', Social Science and Medicine 76(1): 67-73.

Borghi, J., Maluka, S., Kuwawenaruwa, A., Makawia, S., Tantau, J., Mtei, G, Ally, M. and Macha, J. (2013) 'Promoting universal financial protection: A case study of new management of community health insurance in Tanzania', Health Research Policy and Systems 11: 21.

Cochran, W.G. (1977) Sampling Techniques, 3rd edn, New York: John Wiley \& Sons, p. 21.

Danis, M., Binnendijk, E., Vellakkal, S., Ost, A., Koren, R. and Dror, D.M. (2007) 'Eliciting the health insurance benefit choices of low income populations in India with the CHAT exercise', Economic and Political Weekly 42(32): 3331-3339.

Dror, D.M. and Armstrong, J. (2006) 'Do micro health insurance units need capital or reinsurance? A simulated exercise to examine different alternatives', The Geneva Papers on Risk and Insurance-Issues and Practice 31(4): 739-761.

Dror, D.M. and Koren, R. (2012) 'The elusive quest for estimates of willingness to pay for health microinsurance among the poor in low income countries', in C. Churchill and M. Matul (eds) Protecting the Poor: A Microinsurance Compendium, Vol. II, Geneva: International Labour Organization, pp. 156-173.

Dror, D.M., Koren, R., Ost, A., Binnendijk, E., Vellakkal, S. and Danis, M. (2007) 'Health insurance benefit packages prioritized by low-income clients in India: Three criteria to estimate effectiveness of choice', Social Science and Medicine 64(4): 884-896.

\footnotetext{
${ }^{37}$ http://www.rockefellerfoundation.org/.

38 http://www.misereor.org/ http://www.misereor.org/.
} 
Dror, D.M. and Radermacher, R. (2010) 'Financial inclusion opportunities for micro health insurance in Nepal', from http://ssrn.com/abstract=1548870, accessed 1 March 2013.

Dror, D.M., Radermacher, R. and Koren, R. (2007) 'Willingness to pay for health insurance among rural and poor persons: Field evidence from seven micro health insurance units in India', Health Policy 82(1): 12-27.

Dror, D.M., van Putten-Rademaker, O. and Koren, R. (2008) 'Cost of illness: Evidence from a study in five resource-poor locations in India', Indian Journal of Medical Research 127(4): 347-361.

Garg, C.C. and Karan, A.K. (2009) 'Reducing out of pocket expenditures to reduce poverty: A disaggregated analysis at rural-urban and state level in India', Health Policy and Planning 24(2): 116-128.

GIZ Health Sector Support Program, Department of Health Services (2012) Review of Community-Based Health Insurance Initiatives in Nepal. December 2012, Teku, Kathmandu: Commissioned by BMZ and P4H.

Mahal, A., Krishnaswamy, K., Ruchismita, R. and Babu, B.G. (2013) 'What is a health card worth? A randomized controlled trial of an outpatient health insurance product in rural India', The Lancet 381(sup.2): S87.

Narayan, D., Patel, R., Schafft, K., Rademacher, A. and Koch-Schulte, S. (2000) Voices of the Poor: Can Anyone Hear Us? New York: Oxford University Press (for the World Bank).

Panda, P., Chakraborty, A. and Dror, D.M. (2013) Building Awareness to Health Insurance among the Target population of Community-Based Health Insurance Schemes in Rural India (mimeo).

Pott, J. and Holtz, J. (2013) 'Value-added services in health microinsurance', Microinsurance Paper No 19, International Labour Organization, from http://www.ilo.org/public/english/employment/mifacility/download/ mpaper19_services.pdf, accessed 1 March 2013.

Ryan, M., Scott, D.A., Reeves, C., Bate, A., van Teijlingen, E.R., Russell, E.M., Napper, M. and Robb, C.M. (2001) 'Eliciting public preferences for healthcare: A systematic review of techniques', Health Technology Assessment 5(5): $1-186$.

Som, R.K. (1996) Practical Sampling Techniques, New York: M Dekker.

Stoermer, M. (2012) Community based health insurance (CBHI) schemes in Nepal: An evaluation of their performance and potential contribution to healthcare financing, paper presented at the 2012 European Conference on Health Economics, Zurich.

Wipf, J. and Garand, D. (2010) Performance Indicators for Microinsurance: A Handbook for Microinsurance Practitioners, Luxembourg: ADA asbl.

World Bank (2007) 'Out of pocket health expenditure (\% of private expenditure on health)', from http://data. worldbank.org/indicator/SH.XPD.OOPC.ZS, accessed 1 March 2013.

WHO (2011) 'Health financing for universal coverage and social health protection: Bridging the health-care divide: A background paper for the development of national health financing strategy, Kathmandu', from http://www. who.int/providingforhealth/countries/HFBackgroundPaper.pdf, accessed 1 March 2013.

Xu, K., Saksena, P., Jowett, M., Indikadahena, C., Kutzin, J. and Evans, D.B. (2010) 'Exploring the thresholds of health expenditure for protection against financial risk', World Health Report 2010, Background paper No. 19. 


\section{Appendix A}

MIA Implementation Model - Timeline

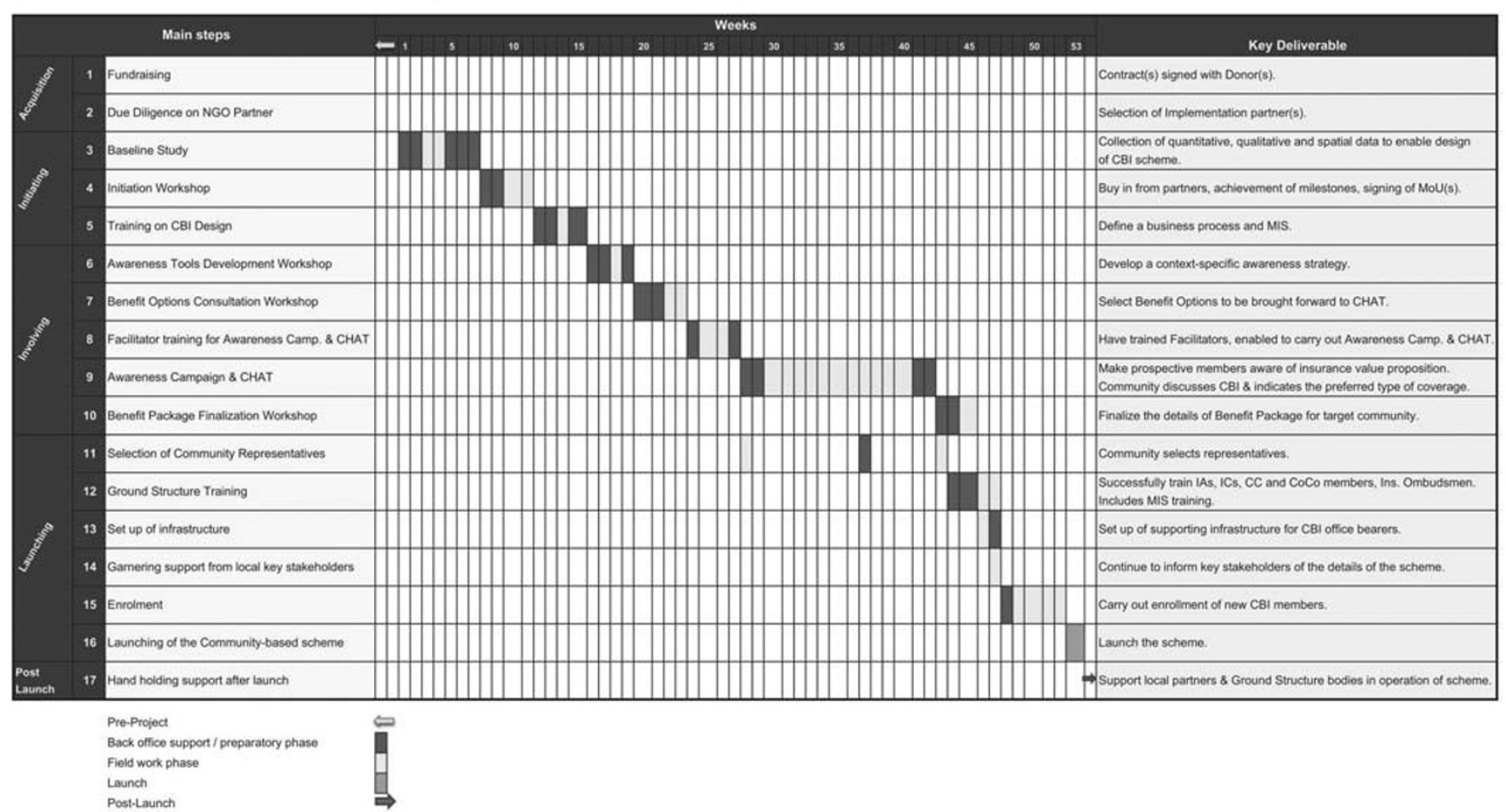

Figure A1. Details of the MIA implementation process. 
Appendix B

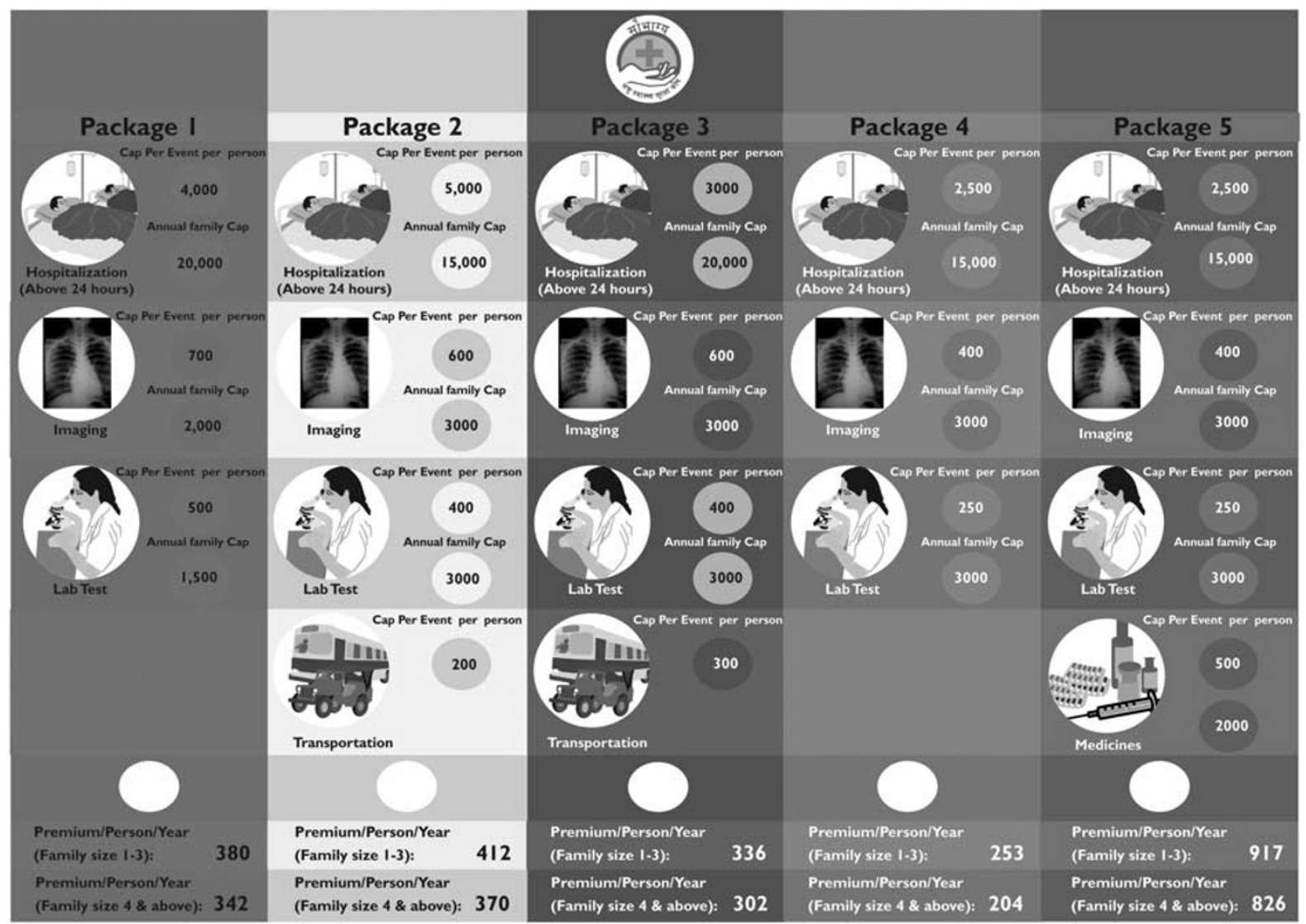

Figure B1. CHAT board describing various benefit packages, prepared by MIA 


\section{About the Authors}

David M. Dror, PhD, DBA, is the Chairman of the Micro Insurance Academy and Honorary Professor at Institute of Health Policy and Management, Erasmus University Rotterdam.

Atanu Majumdar MSc, a Statistician, is Senior Research Consultant at the Micro Insurance Academy (MIA), India.

Pradeep Panda, $\mathrm{PhD}$, an Economist and a Demographer, is Director of Research at the Micro Insurance Academy (MIA), India.

Denny John, MPH, is Deputy Director of Implementation at the Micro Insurance Academy (MIA), India.

Ruth Koren PhD is a Professor at Tel Aviv University Medical School, Israel.

This work is licensed under a Creative Commons Attribution 3.0 Unported License. To view a copy of this license, visit http://creativecommons.org/ licenses/by/3.0/ 